\title{
Post-synthesis modification of porous organic polymers with amine: a task-specific microenvironment for $\mathrm{CO}_{2}$ capture
}

\author{
Yankai $\mathrm{Li}^{1} \cdot \mathrm{Li}$ Yang $^{1} \cdot \mathrm{Xiang}_{\mathrm{Zhu}}{ }^{1} \cdot \mathrm{Jun} \mathrm{Hu}^{1} \cdot \mathrm{Honglai}_{\mathrm{Liu}}{ }^{1}$
}

Received: 25 January 2016/Revised: 24 September 2016/Accepted: 1 November 2016/Published online: 28 November 2016

(C) The Author(s) 2016. This article is published with open access at Springerlink.com

\begin{abstract}
A porous organic polymer named FC-POP was facilely synthesized with extraordinary porosity and excellent stability. Further covalent incorporation of various amines including single amine group, multi-amine groups of diethylenediamine (DETA), and poly-amine groups of polyethylenimine (PEI) to the network gave rise to task-specific modification of the microenvironments to make them more suitable for $\mathrm{CO}_{2}$ capture. As a result, significant boost of $\mathrm{CO}_{2}$ adsorption capacity of $4.5 \mathrm{mmol} / \mathrm{g}$ (for FC-POP- $\mathrm{CH}_{2} \mathrm{DETA}, 273 \mathrm{~K}, 1 \mathrm{bar}$ ) and the $\mathrm{CO}_{2} / \mathrm{N}_{2}$ selectivity of 736.1 (for FCPOP- $\mathrm{CH}_{2} \mathrm{PEI}$ ) were observed after the post-synthesis amine modifications. Furthermore, these materials can be regenerated in elevated temperature under vacuum without apparent loss of $\mathrm{CO}_{2}$ adsorption capacity.
\end{abstract}

Keywords Porous organic polymers $\cdot$ Friedel-Crafts alkylation $\cdot$ Post-synthesis $\cdot$ Amine modification $\cdot \mathrm{CO}_{2}$ capture

\section{Introduction}

The rapidly increasing concentration of atmospheric carbon dioxide generated from combustion of fuels (include coal, petroleum and natural gas) has aroused environmental concern, as a result, carbon capture and sequestration (CCS) gradually gain their growing popularity (D'Alessandro et al. 2010; Sumida et al. 2011; Goeppert et al. 2012; Lu et al. 2013; Wang and Xu 2014; Romanov et al. 2015). Chemical absorption by aqueous solutions of ethanolamines (Brennecke and Gurkan 2010), which is most widely used CCS technique, suffer from several fatal defects including solvent loss, corrosion, and tremendous energy cost for the regeneration (Service 2004). So more efforts have been devoted to solid porous adsorbent. Various categories of novel materials with extraordinary porosity have been discovered, including silicas (Suhendi

Jun $\mathrm{Hu}$

junhu@ecust.edu.cn

1 State Key Laboratory of Chemical Engineering, Department of Chemistry, East China University of Science and Technology, Shanghai 200237, China et al. 2013), zeolites (Wakihara et al. 2010), metal-organic frameworks ( $\mathrm{Li}$ et al. 2014), zeolitic imidazolate frameworks (Cai et al. 2014) and carbon materials (Sevilla and Fuertes 2011). With the advantages of outstanding BET surface area and stability, tremendous porous organic polymers (POPs) have been designed (Jiang et al. 2009; Dawson et al. 2012; Zhao et al. 2012; Han et al. 2013; Liu et al. 2013; Zhu et al. 2013; Thompson et al. 2014; Zhu and Zhang 2014; Puthiaraj et al. 2015). More importantly, the organic skeletons of POPs give rise to their easy-to-functionalize nature so that enhancement of $\mathrm{CO}_{2} / \mathrm{N}_{2}$ selectivity is able to be realized via the incorporation of $\mathrm{CO}_{2}$-philic groups into networks (Thomas 2010). Typically, PPNs (porous polymer networks) (Ben et al. 2009; Yuan et al. 2011) was synthesized with ultrahigh Brunner-EmmetTeller (BET) surface area, the specific surface area of materials calculated by using adsorption theory developed by three scientists, namely Brunner, Emmet and Teller), some of which can be further incorporated by various groups, such as sulfonic acid, lithium sulfonate and ammonium sulfonate, to significantly improve the $\mathrm{CO}_{2}$ uptake $(3.6-3.7 \mathrm{mmol} / \mathrm{g}, \quad 295 \mathrm{~K}, 1 \mathrm{bar}$ ) (Lu et al. 2011, 2013). However, in spite of their impressive performance, these polymers are difficult to be used for 
industrial scale-up applications because of the harsh synthesis conditions.

Alternatively, a facile and efficient method has been reported, known as "knitting" aromatic building blocks to a polymeric skeleton. A large number of heterocyclic rings were picked as monomers to afford crosslinking networks by applying the new technique ( $\mathrm{Li}$ et al. 2011; Woodward et al. 2014; Zhu et al. 2014; Xu et al. 2015). However, their modest $\mathrm{CO}_{2}$ uptakes need great improvement for the future $\mathrm{CO}_{2}$ capture applications (Luo et al. 2012).

Herein, a single-step procedure was adopted to facilely realize "knitting" strategy to afford a porous organic polymer via Friedel-Crafts alkylation (FC-POPs). Triptycene, which may allow for a high degree of internal free volume, was chosen as monomer, in order to deliver FCPOPs with abundant mesopores. The mesopores of FCPOPs shows a facility for further modifications, to investigate the influence of pore structure and nitrogen-site density on $\mathrm{CO}_{2}$ adsorption. To realize this fancy, various groups with nitrogen-site including amine-group, diethylenediamine (DETA) and polyethylenimine (PEI) were grafted into the network to produce task-specific microenvironments by modifying microporosity and nitrogen-site density (Scheme. 1). Accordingly, the $\mathrm{CO}_{2}$ adsorption capacity and selectivity of $\mathrm{CO}_{2}$ over $\mathrm{N}_{2}$ were significantly improved after the post-synthesis modifications.

\section{Experiments}

\subsection{Materials and synthesis}

Solvents, reagents and chemicals were purchased from Aldrich and TCI. All were used without any further purification.

\subsubsection{Synthesis of FC-POP}

Similar to Tan's method ( $\mathrm{Li}$ et al. 2011), Triptycene $(0.64 \mathrm{~g}, 2.5 \mathrm{mmol})$ and formaldehyde dimethyl acetal $(1.14 \mathrm{~g}, 15.0 \mathrm{mmol})$ dissolving in $5 \mathrm{~mL}$ dichloroethane was added to a $25 \mathrm{~mL}$ flask. Anhydrous $\mathrm{FeCl}_{3}(2.44 \mathrm{~g}$, $15.0 \mathrm{mmol}$ ) was then added as a catalyst, and the mixture was stirred at $45^{\circ} \mathrm{C}$ for $5 \mathrm{~h}$ and then heated to $80{ }^{\circ} \mathrm{C}$ for another $19 \mathrm{~h}$. After cooling to room temperature, the mixture was filtered, washed by methanol for 3 times. The solid was collected, and extracted with methanol by Soxhlet apparatus for $24 \mathrm{~h}$, brown solid was obtained after drying (yield $\sim 95 \%$ ).

\subsubsection{Synthesis of $\mathrm{FC}-\mathrm{POP}-\mathrm{CH}_{2} \mathrm{Cl}$}

A mixture of $0.30 \mathrm{~g}$ FC-POP, $1.50 \mathrm{~g}$ paraformaldehyde, $9.0 \mathrm{~mL}$ acetic acid, $4.5 \mathrm{~mL}$ phosphoric acid and $30.0 \mathrm{~mL}$ concentrated hydrochloric acid were charged in a flask, by

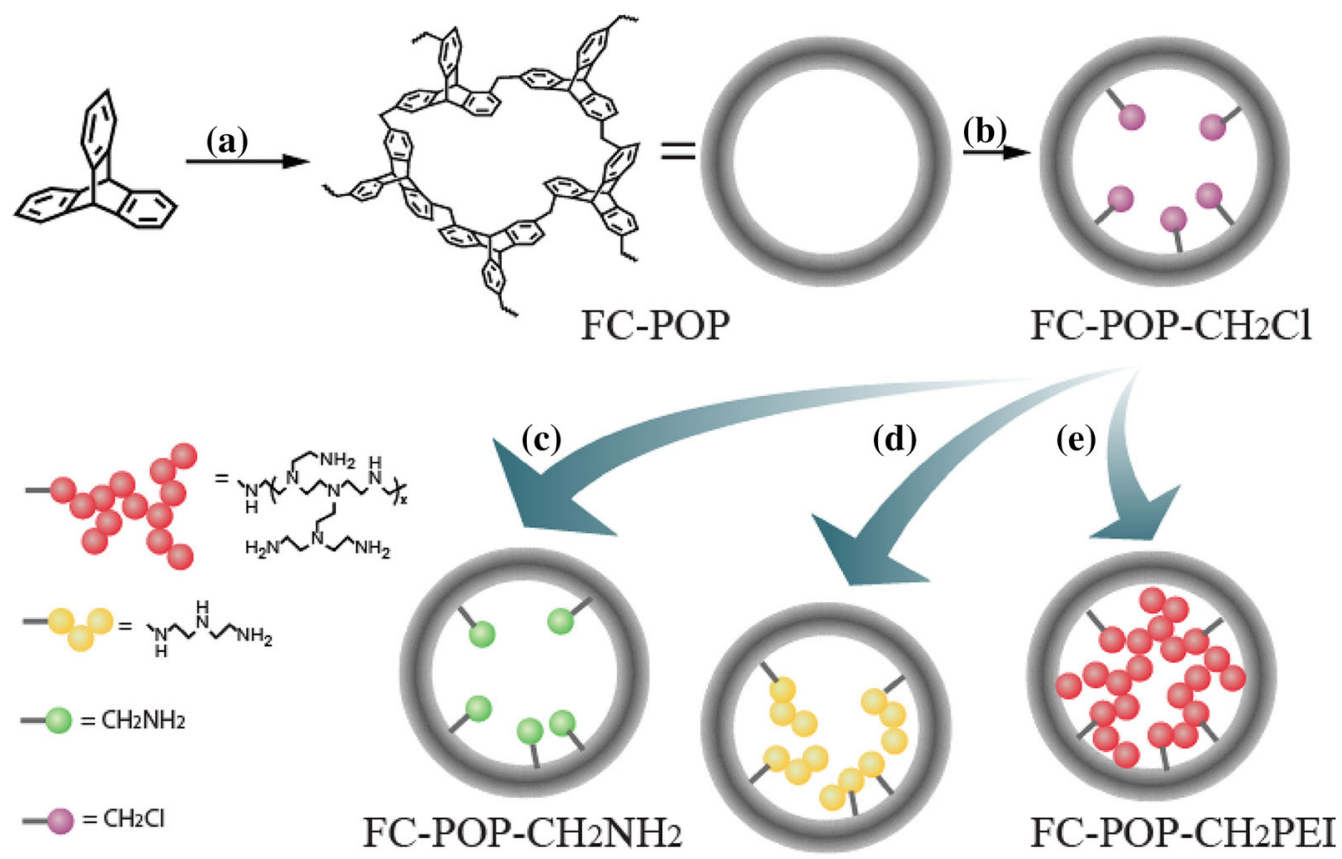

FC-POP-CH2DETA

Scheme 1 Synthesis of FC-POP and its derivatives. The reaction conditions in each step; a formaldehyde dimethyl acetal, $\mathrm{FeCl}_{3}$, dichloroethane, $45{ }^{\circ} \mathrm{C}, 5 \mathrm{~h} ; 80{ }^{\circ} \mathrm{C}, 19 \mathrm{~h}$; b paraformaldehyde, $\mathrm{H}_{3} \mathrm{PO}_{4}, \mathrm{AcOH}, \mathrm{HCl}, 90{ }^{\circ} \mathrm{C}, 72 \mathrm{~h}$; c i potassium phthalimide, DMF, $100{ }^{\circ} \mathrm{C}, 8 \mathrm{~h}$; ii hydrazine monohydrate, EtOH, reflux, $20 \mathrm{~h}$; d DETA, $90^{\circ} \mathrm{C}, 72 \mathrm{~h}$; e PEI, $90{ }^{\circ} \mathrm{C}, 72 \mathrm{~h}$ 
following a well-known method (Lu et al. 2012). The flask was sealed, then the mixture was heated to $90{ }^{\circ} \mathrm{C}$ and maintained for 3 days. After cooling to room temperature, the solid was collected and washed with water and methanol for three times, then dried to afford FC-POP$\mathrm{CH}_{2} \mathrm{Cl}$.

\subsubsection{Synthesis of $\mathrm{FC}-\mathrm{POP}-\mathrm{CH}_{2} \mathrm{NH}_{2}$}

A mixture of FC-POP- $\mathrm{CH}_{2} \mathrm{Cl}(0.20 \mathrm{~g})$, potassium phthalimide $(1.19 \mathrm{~g})$ and $20.0 \mathrm{~mL} N, N$-dimethylformamide (DMF) was stirred at $100{ }^{\circ} \mathrm{C}$ for $8 \mathrm{~h}$ under an argon atmosphere, similar to a well-known method (Ilhan et al. 1999). The cooled mixture was filtered and cursorily washed by DMF. The resulting phthalimide derivative was mixed with $1 \mathrm{~mL}$ of hydrazine monohydrate in $12 \mathrm{~mL}$ ethanol. The reaction was refluxed for $20 \mathrm{~h}$. The reaction mixture was filtered and washed subsequently by DMF, water and $\mathrm{MeOH}$, then dried to afford $\mathrm{FC}-\mathrm{POP}-\mathrm{CH}_{2} \mathrm{NH}_{2}$.

\subsubsection{Synthesis of $\mathrm{FC}-\mathrm{POP}-\mathrm{CH}_{2} \mathrm{DETA}$}

A mixture of $0.10 \mathrm{~g}$ FC-POP- $\mathrm{CH}_{2} \mathrm{Cl}$ and $10.0 \mathrm{~mL}$ diethylenetriamine (DETA) was charged in a flask, according to a well-known method ( $\mathrm{Lu}$ et al. 2012). The flask was sealed then heated to $90{ }^{\circ} \mathrm{C}$ and maintained for 3 days. After cooling to room temperature, the solid was collected and washed with water and methanol for several times, then dried to afford FC-POP- $\mathrm{CH}_{2}$ DETA.

\subsubsection{Synthesis of $\mathrm{FC}-\mathrm{POP}-\mathrm{CH}_{2} \mathrm{PEI}$}

In a fashion similar to the synthesis of FC-POP- $\mathrm{CH}_{2}$ DETA, $0.10 \mathrm{~g}$ FC-POP- $\mathrm{CH}_{2} \mathrm{Cl}$ and $10.0 \mathrm{~g}$ polyethylene imine (PEI, $\mathrm{mw}=600)$ was reacted to afford FC-POP- $\mathrm{CH}_{2}$ PEI.

\subsection{Characteristics}

Thermogravimetry analysis (TGA) were performed under $\mathrm{N}_{2}$ on a NETZSCH STA449F3, with a heating rate of $10{ }^{\circ} \mathrm{C}$ /min. ${ }^{13} \mathrm{C}$ NMR measurements were performed on a $9.4 \mathrm{~T}$ Bruker Avance spectrometer at a Larmor frequency of 100.6 MHz. Measurements were made with a $4 \mathrm{~mm}$ MAS probe spinning at $15 \mathrm{kHz}$. Chemical shifts were externally referenced to TMS ( $\delta=0 \mathrm{ppm})$ using the methyl resonance of hexamethylbenzene (17.5 ppm relative to TMS). Nitrogen adsorption isotherms were measured at $77 \mathrm{~K}$ using Micromeritics ASAP 2020 static volumetric analyzer. Before adsorption measurements the polymer was degassed at $110{ }^{\circ} \mathrm{C}$ under vacuum. The BET surface area was calculated within the relative pressure range $0.05-0.30$. Total volume was calculated at $p / p_{0}=0.98$ and micropore volume was calculated by t-plot method. FTIR data were obtained using a Nicolet Magna-IR 550 spectrometer. Elemental analysis was determined using a Vario EL III Elemental Analyzer (Elementar, Germany).

\subsection{Gas adsorption experiments}

\subsubsection{Gas adsorption and desorption isotherms}

Both of gas adsorption and desorption isotherms of POPs were measured using a Micromeritics ASAP 2020 static volumetric analyzer at the setting temperature. Prior to each adsorption experiment, the samples were degassed for $12 \mathrm{~h}$ at $110^{\circ} \mathrm{C}$ ensuring that the residual pressure fell below $0.2 \mathrm{~Pa}$ and then cooled down to the target temperatures, followed by introduction of a single component gas $\left(\mathrm{CO}_{2}\right.$ or $\left.\mathrm{N}_{2}\right)$ into the system. Once the adsorption process finished, the desorption experiment was automatically initiated. In the desorption stage, gas pressure gradually decreased and the corresponding amount of residue adsorbed gas was measured and calculated by the instrument.

\subsubsection{Fits of isotherms}

For FC-POP and FC-POP- $\mathrm{CH}_{2} \mathrm{Cl}$, single-site Langmuir fit is appropriate. Their isotherms can be described by the Eq. (1).

$q=q_{\mathrm{sat}} \frac{b p}{1+b p}$

where, $b$ is a parameter in the pure component Langmuir isotherm $\left(\mathrm{Pa}^{-1}\right), p$ represents gas pressure $(\mathrm{Pa}), q$ is molar loading of gas components $(\mathrm{mol} / \mathrm{kg})$ and $q_{\mathrm{sat}}$ is saturation capacity of gas components ( $\mathrm{mol} / \mathrm{kg}$ ).

For FC-POP- $\mathrm{CH}_{2} \mathrm{NH}_{2}$, FC-POP- $\mathrm{CH}_{2}$ DETA and FC$\mathrm{POP}-\mathrm{CH}_{2} \mathrm{PEI}$, both physical and chemical interaction should be taken into account so that dual-site Langmuir (Eq. 2) fitting is fine.

$q=q_{\mathrm{sat}, 1} \frac{b_{1} p}{1+b_{1} p}+q_{\mathrm{sat}, 2} \frac{b_{2} p}{1+b_{2} p}$

where two distinct adsorption sites are assumed to be existed, so there are four parameters in the equation, namely $q_{\mathrm{sat}, 1}, b_{1}, q_{\mathrm{sat}, 2}$ and $b_{2}$.

\subsubsection{Adsorption enthalpy}

For $\mathrm{CO}_{2}$ adsorption, fits of isotherms were used to calculate adsorption enthalpy by employing Clausius-Clapeyron equation (Eq. 3).

$\ln \left(\frac{p_{1}}{p_{2}}\right)=\Delta H\left(\frac{1}{T_{1}}-\frac{1}{T_{2}}\right)$ 
where $p_{i}$ is the pressure for isotherm $i, T_{i}$ is the temperature for isotherm $i, R$ is $8.315 \mathrm{~J} /(\mathrm{K} \mathrm{mol})$.

\subsubsection{IAST calculation}

Pure-component isotherm fitting parameters were used for calculating ideal adsorbed solution theory (IAST) binarygas adsorption selectivity (Myers and Prausnitz 1965), defined as the Eq. (4):

$S=\frac{q_{1} / q_{2}}{p_{1} / p_{2}}$

where $p_{i}$ represents partial pressure of gas $i$ and $q_{i}$ is the corresponding pure-component gas uptake amount at $p_{i}$. The IAST calculations were carried out for flue gas model (binary mixture containing $15 \% \mathrm{CO}_{2}$ and $85 \% \mathrm{~N}_{2}$ ).

\section{Results and discussions}

\subsection{General characteristics}

FC-POP was synthesized in good yield via a simple Friedel-Crafts reaction. Triptycene was selected to be the monomer because of its rigid molecular structure, which would lead to a microporous skeleton with the extraordinary porosity and high stability. The resulting FC-POP was found to be insoluble in common organic solvents, such as water, methanol, dichloromethane, tetrahydrofuran, acetone and hexane. The chemical structure of FC-POP was confirmed by ${ }^{13} \mathrm{C}$ cross-polarization magic-angle spinning (CP/MAS) NMR (Fig. 1). In the NMR spectrum, the resonance peaks at 139 and $130 \mathrm{ppm}$ correspond to the substituted aromatic carbons of triptycene, while the resonance peak at 120 correspond to their non-substitute counterparts. Resonance peaks at $46-50$ belong to the bridgehead carbons of triptycene. The peaks around $32 \mathrm{ppm}$ ascribes to the carbons of methylene linkers. Besides, high thermostability of FC-POP was proved by thermogravimetric analysis (TGA) that little apparent weight loss below $350{ }^{\circ} \mathrm{C}$ (Fig. 2a).

In order to modify the microenvironment, FC-POP was covalently incorporated by various moieties to obtain a series of amine-functionalized FC-POPs (Scheme 1). FCPOP- $\mathrm{CH}_{2} \mathrm{Cl}$, which containing vivacious chloromethyl groups, was first been prepared as an intermediate and chloromethyl groups were then substituted by various amines to afford FC-POP- $\mathrm{CH}_{2} \mathrm{NH}_{2}$, FC-POP- $\mathrm{CH}_{2}$ DETA and $\mathrm{FC}-\mathrm{POP}-\mathrm{CH}_{2} \mathrm{PEI}$. The peaks at $75-93 \mathrm{ppm}$ in the solid-state NMR spectrum of FC-POP- $\mathrm{CH}_{2} \mathrm{Cl}$ suggested the graft of chloromethyl to the polymeric skeleton (Fig. 1). The appearance of peaks around $200 \mathrm{ppm}$ for the

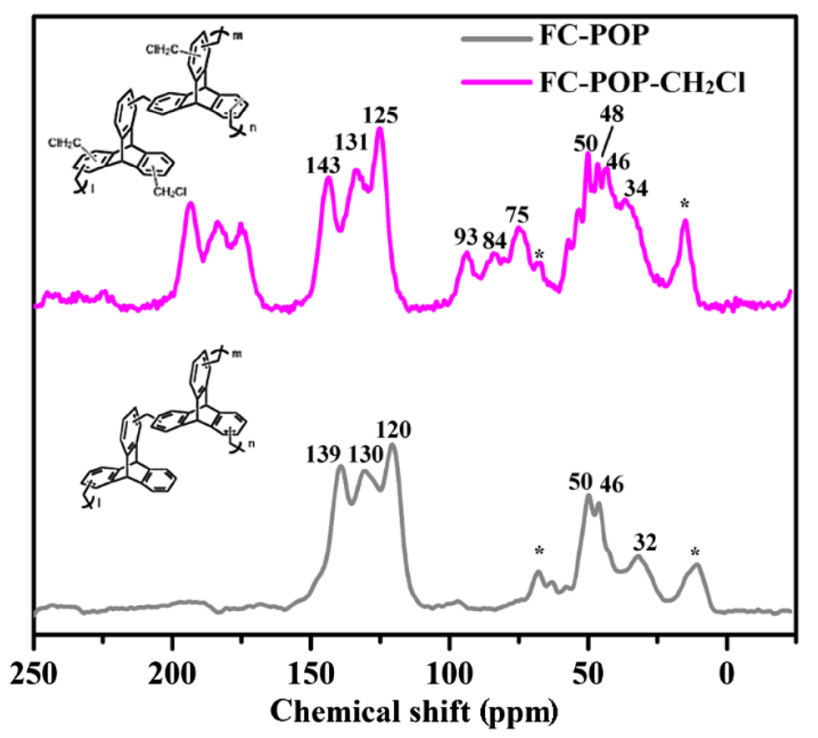

Fig. 1 Solid State ${ }^{13} \mathrm{C}$ cross-polarization magic-angle spinning $(\mathrm{CP} /$ MAS) NMR of FC-POP and FC-POP- $\mathrm{CH}_{2} \mathrm{Cl}$

spectrum of $\mathrm{FC}-\mathrm{POP}-\mathrm{CH}_{2} \mathrm{Cl}$ ascribed to the carbonyl group of residual acetic acid and paraformaldehyde that involved in the synthesis. Successful incorporation of functional amine groups were confirmed by Fourier Transform infrared spectroscopy (FTIR) that prosperous graft of amine groups can be proved by enhancement of the band around $1650 \mathrm{~cm}^{-1}$ (Fig. 2b). The amine-modified POPs also exhibit quite good thermal stability according to the thermogravimetric analysis results (Fig. 2a).

To quantitatively describe the density of functional groups, element analysis was conducted for the polymers. The calculated density of nitrogen element $(\mathrm{mmol} / \mathrm{g})$ shows a significant growth of nitrogen density in sequence of FC-POP- $\mathrm{CH}_{2} \mathrm{NH}_{2}(3.46 \mathrm{mmol} / \mathrm{g})$, FC-POP- $\mathrm{CH}_{2}$ DETA $(8.43 \mathrm{mmol} / \mathrm{g})$ and FC-POP-CH ${ }_{2}$ PEI $\quad(11.47 \mathrm{mmol} / \mathrm{g})$ (Table 1). Therefore, the tailor-made functional group would make the nitrogen-site density controllable in the microenvironment of these POPs.

Porosity of these materials was measured by nitrogen adsorption at $77 \mathrm{~K}$ (Fig. 3a) and the surface areas were calculated by the BET model. FC-POP exhibits extraordinary porosity, with the BET surface area as high as $1540 \mathrm{~m}^{2} / \mathrm{g}$. The adsorption/desorption isotherms for FCPOP is not closed, mainly because of a swelling of polymer matrix at $77 \mathrm{~K}$ (Zhang et al. 2012). After the incorporation of functional groups, the BET surface area dropped correspondingly. The $S_{\mathrm{BET}}$ data drops to $939 \mathrm{~m}^{2} / \mathrm{g}$ for FCPOP- $\mathrm{CH}_{2} \mathrm{NH}_{2}, 636 \mathrm{~m}^{2} / \mathrm{g}$ for FC-POP-CH $\mathrm{CH}_{2}$ DETA and only $129 \mathrm{~m}^{2} / \mathrm{g}$ for FC-POP-CH $\mathrm{CH}_{2}$ PEI. For the adsorption isotherms of these FC-POPs, swift climb at low pressure $(p /$ $\left.p_{0}<0.001\right)$ is contributed by micropores of these FCPOPs, while hysteresis at higher pressure proves the 

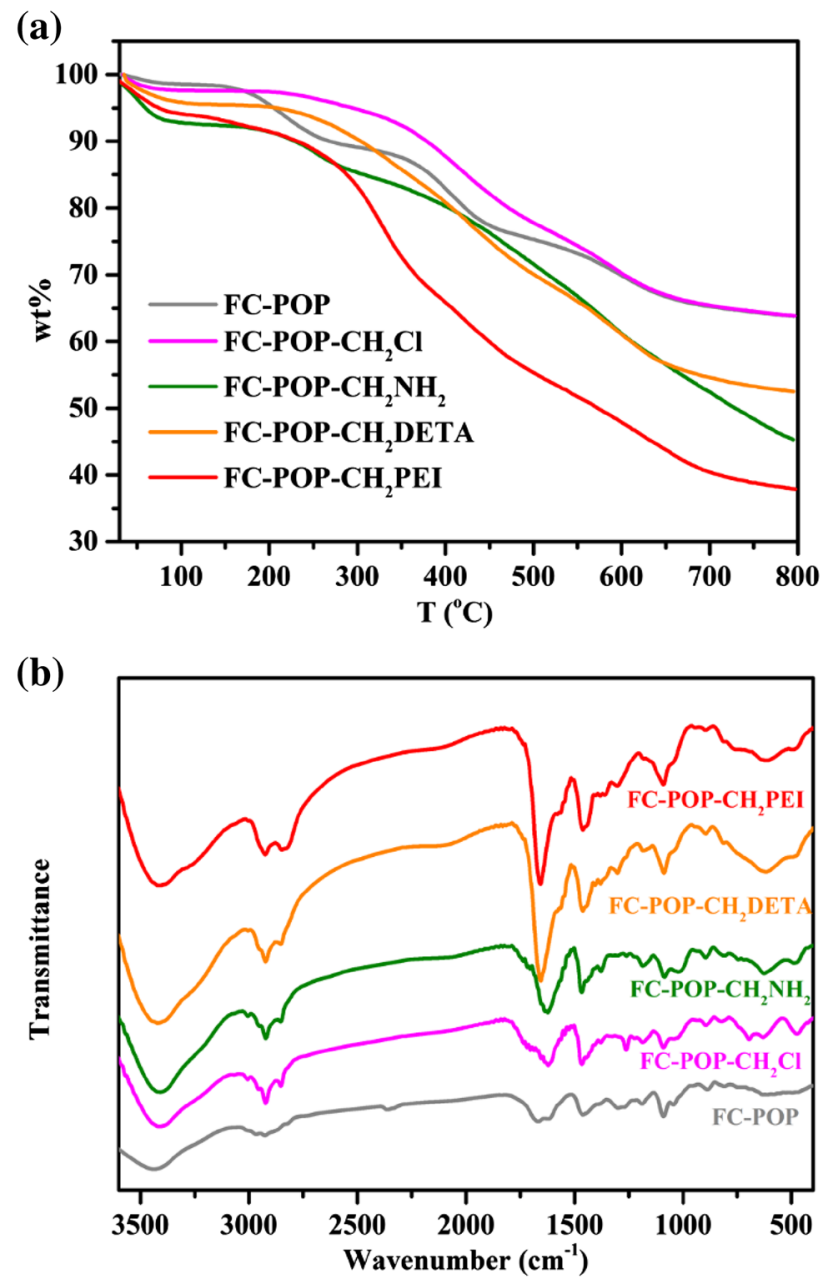

Fig. 2 Thermogravimetric analysis (TGA) (a) and Fourier Transform infrared spectroscopy (FTIR) (b) of FC-POP, FC-POP- $\mathrm{CH}_{2} \mathrm{Cl}$, FCPOP- $\mathrm{CH}_{2} \mathrm{NH}_{2}$, FC-POP-CH${ }_{2}$ DETA and FC-POP-CH

existence of mesopores. Pore size distribution caculated by non-local density functional theory (NLDFT) method also confirmed the presence of both micropores and mesopores (Fig. 3b). The mesopores, facilitating the mass transfer during the gas uptake process, can act as the transport channels (Liao et al. 2014). On the other hand, micropores, enhancing the interaction between the wall and $\mathrm{CO}_{2}$ molecules, can act as the adsorption active points
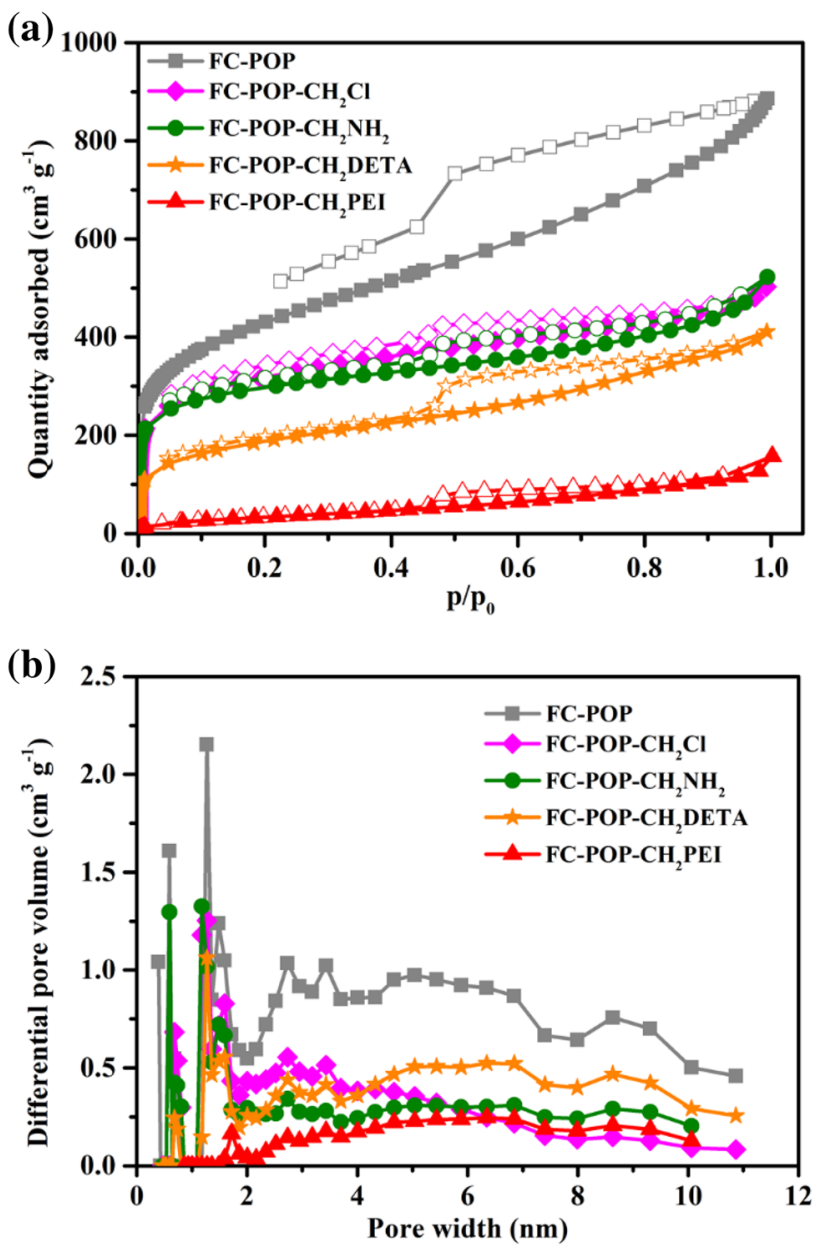

Fig. 3 a Nitrogen adsorption isotherms at $77 \mathrm{~K}$, solid symbols for adsorption curves and hollow symbols for desorption ones; $\mathbf{b}$ pore size distribution calculated by NLDFT method

(Islamoglu et al. 2013). As a result, both of them are crucial to $\mathrm{CO}_{2}$ adsorption applications. For FC-POP, $V_{\text {micro }} / V_{\text {total }}$ value (the ratio of micropore volume to the total pore volume) is as low as 0.0842 , demonstrating the existance of impressive mesopores. After grafting amines into the network, the microenvironment of pore structure has altered. For example, $V_{\text {micro }}$ value of $\mathrm{FC}-\mathrm{POP}-\mathrm{CH}_{2} \mathrm{NH}_{2}$ $\left(0.251 \mathrm{~cm}^{3} / \mathrm{g}\right)$ doubles that of FC-POP $\left(0.113 \mathrm{~cm}^{3} / \mathrm{g}\right)$, and its $V_{\text {micro }} / V_{\text {total }}$ value upsurges to 0.311 . Accordingly, the

Table 1 Elemental analysis and calculated $\mathrm{N}$-site density for FC-POP, FC-POP-CH ${ }_{2} \mathrm{Cl}, \mathrm{FC}-\mathrm{POP}-\mathrm{CH}_{2} \mathrm{NH}_{2}$, FC-POP-CH${ }_{2} \mathrm{DETA}$ and FC-POP$\mathrm{CH}_{2}$ PEI

\begin{tabular}{lcccc}
\hline POPs & $\mathrm{N}(\%)$ & $\mathrm{C}(\%)$ & $\mathrm{H}(\%)$ & $\mathrm{N}$-site density $(\mathrm{mmol} \mathrm{N} / \mathrm{g})$ \\
\hline FC-POP & $\sim 0$ & 77.78 & 4.89 & $\sim 0$ \\
FC-POP-CH${ }_{2} \mathrm{Cl}$ & $\sim 0$ & 71.60 & 5.34 & $\sim 0$ \\
FC-POP-C $\mathrm{CH}_{2} \mathrm{NH}_{2}$ & 4.10 & 73.93 & 6.56 & 3.46 \\
FC-POP-CH $\mathrm{CH}_{2}$ DETA & 10.79 & 73.21 & 7.47 & 8.43 \\
FC-POP- $\mathrm{CH}_{2}$ PEI & 14.53 & 67.90 & 8.04 & 11.47 \\
\hline
\end{tabular}



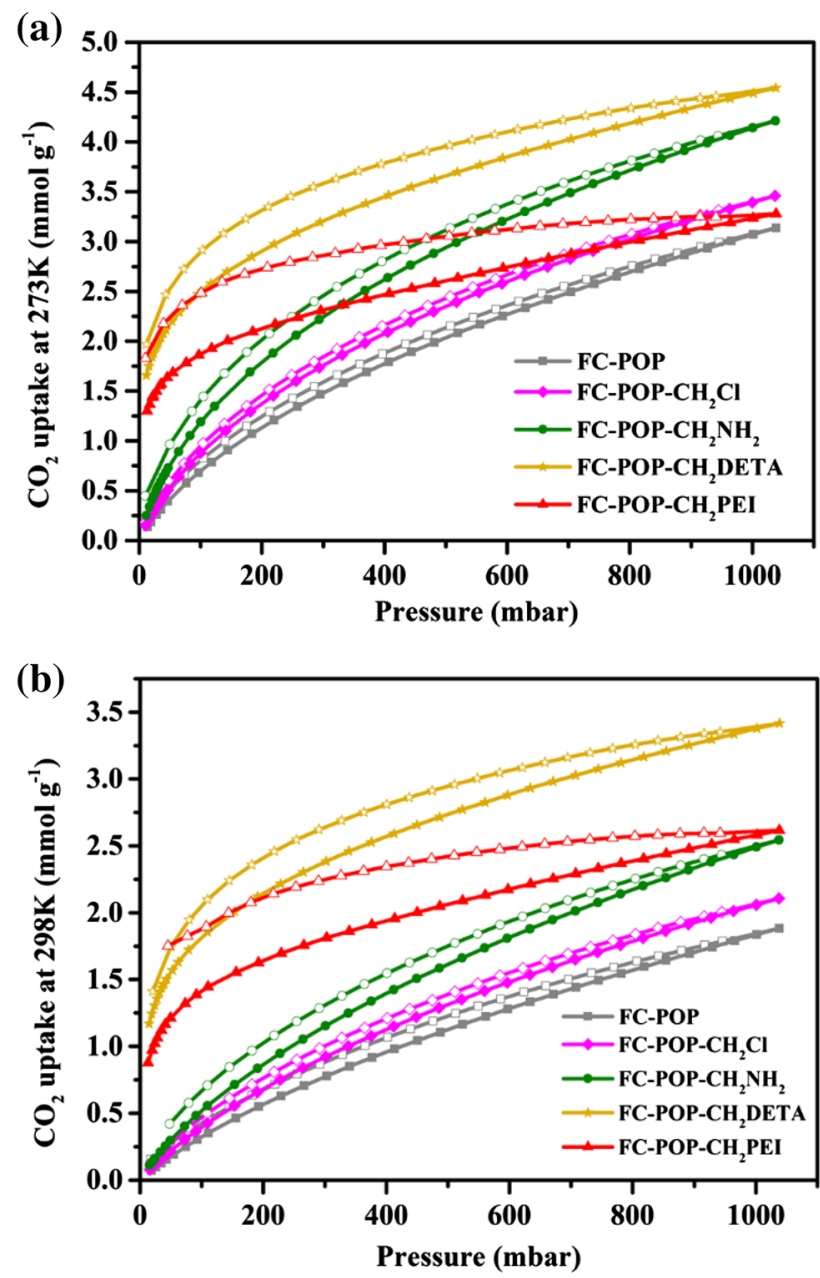

Fig. $4 \mathrm{CO}_{2}$ adsorption isotherms measured at $273 \mathrm{~K}$ (a) and $298 \mathrm{~K}$ (b), solid symbols for adsorption curves and hollow symbols for desorption ones

incorporation of functional groups may spatially separate mesopores into several micropores, result in the modified microenvironment of these FC-POPs through the redistribution of pore volumes, making the resulting POPs more suitable for $\mathrm{CO}_{2}$ capture applications.

\section{2 $\mathrm{CO}_{2}$ adsorption performance}

Excellent porosity and affluent nitrogen density are beneficial to boost $\mathrm{CO}_{2}$ adsorption capacity for these aminemodified POPs. Indeed, significant growth of $\mathrm{CO}_{2}$ uptake was observed after amine-grafting (Fig. 4). For FC-POP$\mathrm{CH}_{2} \mathrm{NH}_{2}$ and FC-POP- $\mathrm{CH}_{2}$ DETA, under the pressure of 1 bar, $\mathrm{CO}_{2}$ adsorption capacity reaches $4.2 / 2.5$ and $4.5 /$ $3.4 \mathrm{mmol} / \mathrm{g}$ at $273 / 298 \mathrm{~K}$, much higher than that of pristine FC-POP (3.1/1.8 mmol/g at 273/298 K). Notably, FCPOP- $\mathrm{CH}_{2} \mathrm{PEI}$ also exhibits impressive $\mathrm{CO}_{2}$ storage ability $(3.2 / 2.6 \mathrm{mmol} / \mathrm{g}$ at $273 / 298 \mathrm{~K})$ in spite of its poor BET surface area. There are two dominant contributions for $\mathrm{CO}_{2}$ adsorption capacity, the chemical adsorption contributed by amine groups (denoted as the nitrogen-site density) and the physical adsorption contributed by porosity (denoted as the BET surface area). For these FC-POPs with diverse incorporated amines, the hysteresis loops between their adsorption/desorption isotherms could be clear evidences of chemical interactions between amine groups and $\mathrm{CO}_{2}$ molecules. However, in our work, the growth of the nitrogen site density can significantly increase the $\mathrm{CO}_{2}$ adsorption enthalpy but decrease the BET surface area (Table 2). FC-POP- $\mathrm{CH}_{2}$ DETA exhibited the excellent $\mathrm{CO}_{2}$ adsorption enthalpy $(54.0 \mathrm{~kJ} / \mathrm{mol})$ yet maintained considerable BET surface area $\left(636 \mathrm{~m}^{2} / \mathrm{g}\right)$. That means, FC-POP- $\mathrm{CH}_{2}$ DETA reached a compromise between these two factors, hence its high $\mathrm{CO}_{2}$ adsorption capacity.

To further understand the influence of various functional groups on adsorption behavior, $\mathrm{CO}_{2}$ adsorption enthalpies were calculated by the dual-site Langmuir fitting of $\mathrm{CO}_{2}$ adsorption isotherms at 273 and $298 \mathrm{~K}$ based on ClausiusClaperyron equation. Figure 5a illustrates a plot of the $\mathrm{CO}_{2}$ adsorption enthalpies as a function of loading. It is obvious

Table 2 Characteristics of POPs in this work

\begin{tabular}{lllllcc}
\hline POPs & $\begin{array}{l}\text { N-site density } \\
(\mathrm{mmol} \mathrm{N} / \mathrm{g})\end{array}$ & $\begin{array}{l}S_{\mathrm{BET}} \\
\left(\mathrm{m}^{2} / \mathrm{g}\right)\end{array}$ & $\begin{array}{l}V_{\text {total }} \\
\left(\mathrm{cm}^{3} / \mathrm{g}\right)^{\mathrm{b}}\end{array}$ & $\begin{array}{l}\mathrm{CO}_{2} \text { uptake }(\mathrm{mmol} / \mathrm{g}) \\
(273 \mathrm{~K} / 298 \mathrm{~K})\end{array}$ & $\begin{array}{l}Q_{\mathrm{st}}^{\mathrm{d}} \\
(\mathrm{kJ} / \mathrm{mol})\end{array}$ & $\begin{array}{l}\text { Selectivity } \\
(298 \mathrm{~K})\end{array}$ \\
\hline FC-POP & $\sim 0$ & 1540 & 1.330 & $3.1 / 1.8$ & 26.4 & 12.62 \\
FC-POP-CHCl & $\sim 0$ & 1058 & 0.801 & $3.4 / 2.1$ & 27.9 & 19.32 \\
FC-POP-CH ${ }_{2} \mathrm{NH}_{2}$ & 3.46 & 939 & 0.808 & $4.2 / 2.5$ & 37.9 & 31.58 \\
FC-POP-CH ${ }_{2}$ DETA & 8.43 & 636 & 0.636 & $4.5 / 3.4$ & 54.0 & 167.8 \\
FC-POP-CH ${ }_{2}$ PEI & 11.47 & 129 & 0.243 & $3.2 / 2.6$ & 59.6 & 736.1 \\
\hline
\end{tabular}

\footnotetext{
${ }^{\text {a }}$ Values were calculated from elemental analysis

b Total volumes calculated at $p / p_{0}=0.98$

c Measured at the pressure of 1 bar

${ }^{\mathrm{d}}$ Calculated $\mathrm{CO}_{2}$ enthalpy of adsorption by applying Clausius-Claperyon equation

${ }^{\text {e }}$ IAST selectivity ( 1 bar) for $\mathrm{CO}_{2} / \mathrm{N}_{2}$ calculated from pure component fits under flue gas model $\left(\mathrm{CO}_{2} / \mathrm{N}_{2}=15: 85\right)$
} 

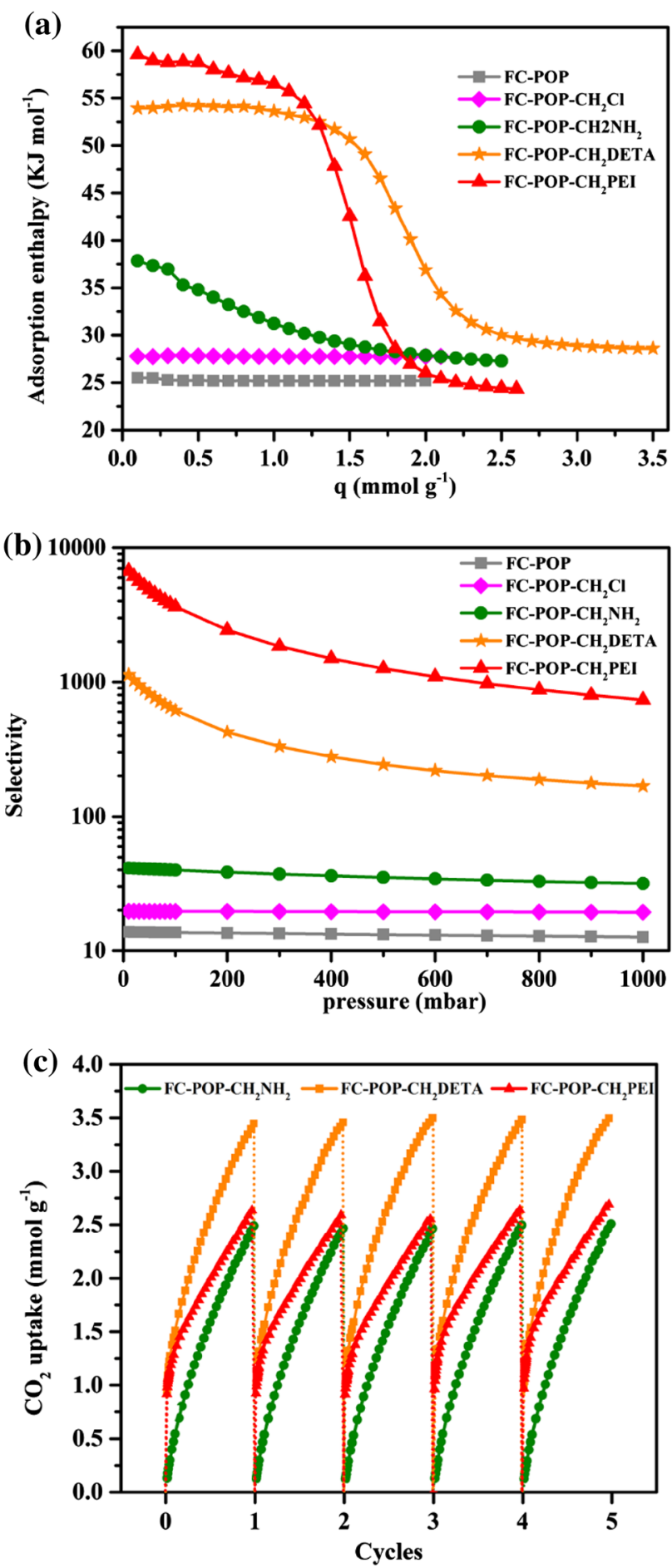

Fig. 5 a $\mathrm{CO}_{2}$ adsorption enthalpy for POPs; b The selectivity of POPs for $\mathrm{CO}_{2}$ over $\mathrm{N}_{2}$ isotherms obtained from IAST calculations; c Cyclic $\mathrm{CO}_{2}$ adsorption for POPs on an ASAP 2020

that FC-POP- $\mathrm{CH}_{2} \mathrm{NH}_{2}, \mathrm{FC}-\mathrm{POP}-\mathrm{CH}_{2}$ DETA and For FCPOP- $\mathrm{CH}_{2} \mathrm{PEI}$ exhibit dramatically high $\mathrm{CO}_{2}$ adsorption enthalpy values as $37.9,54.0$ and $59.6 \mathrm{~kJ} / \mathrm{mol}$ at low loadings, respectively; much higher than that of FC-POP $(26.4 \mathrm{~kJ} / \mathrm{mol})$. The high adsorption enthalpy values ascribe to strong interactions between amine-functional groups in FC-POPs and $\mathrm{CO}_{2}$ molecules, for the presence of amines gives rise to chemical adsorption towards $\mathrm{CO}_{2}$. It is worth mentioned that the adsorption enthalpy value of FC-POP$\mathrm{CH}_{2}$ DETA remains a high value even when the $\mathrm{CO}_{2}$ loading reaches $1.5 \mathrm{mmol} / \mathrm{g}$, suggesting its abundant chemical adsorption sites, hence the extraordinary $\mathrm{CO}_{2}$ adsorption capacity. The adsorption enthalpy values of amine-functionalized POPs show a similar sequence of nitrogen content, so that the nitrogen-site density are the dominant contribution for the strong affinity to $\mathrm{CO}_{2}$ in the microenvironment of these FC-POPs.

The excellent $\mathrm{CO}_{2}$ uptake performance and outstanding adsorptive affinity of these FC-POPs ensure their adsorption selectivity. The ideal adsorption solution theory (IAST) proposed by Myers and Prausnitz (1965) was used to calculate the adsorption selectivity of $\mathrm{CO}_{2} / \mathrm{N}_{2}$ for these materials. Fits of pure component isotherms were plotted to determine the molar uptakes at specified partial pressures in the bulk gas mixture and the selectivity was calculated under the simulated flue gas model $\left(\mathrm{CO}_{2} / \mathrm{N}_{2}=15 / 85\right)$. The results suggested that the presence of incorporated amines in FC-POPs prompts the $\mathrm{CO}_{2} / \mathrm{N}_{2}$ selectivity (Fig. $5 b$ ). The selectivity value of FC-POP- $\mathrm{CH}_{2} \mathrm{NH}_{2}$ (31.58) is about 2.5 times higher than that of FC-POP (12.62) at $298 \mathrm{~K}$. Significantly, the $\mathrm{CO}_{2} / \mathrm{N}_{2}$ selectivity value of FC-POP- $\mathrm{CH}_{2}$ DETA and FC-POP-CH ${ }_{2}$ PEI soar to 167.8 and 736.1 $(298 \mathrm{~K})$, respectively, thanks to their advantageous microenvironment including the microporosity and outstanding nitrogen-site density within the pores. For FCPOP- $\mathrm{CH}_{2} \mathrm{PEI}$, although $\mathrm{CO}_{2}$ uptake seems modest comparing to the reported values [MCTP-1 (Puthiaraj et al. 2015), $2.7 \mathrm{mmol} / \mathrm{g}, 298 \mathrm{~K}$, BILP-4 (Rabbani and El-Kaderi 2012), $3.59 \mathrm{mmol} / \mathrm{g}, 298 \mathrm{~K}$; FCTF-1-600 (Zhao et al. 2013), $3.41 \mathrm{mmol} / \mathrm{g}, 273 \mathrm{~K}$ ], the selectivity value is comparable to many other excellent reported POPs [azo-COP-2 (Patel et al. 2013), 130.6, 298 K; Py-1 (Luo et al. 2012), 117, $273 \mathrm{~K}$; PPN-6-CH${ }_{2}$ DETA (Lu et al. 2012), 442, $295 \mathrm{~K}]$ (Table 3). The excellent selectivity of FC-POP$\mathrm{CH}_{2} \mathrm{PEI}$ ascribe to the strong adsorption enthalpy towards $\mathrm{CO}_{2}(59.6 \mathrm{~kJ} / \mathrm{mol})$. Furthermore, the introduction of PEI moieties can effectively enhance the selectivity, because flexible PEI can block the pores of POPs to interfere the $\mathrm{N}_{2}$ adsorption while $\mathrm{CO}_{2}$ can infiltrate into the void of PEI chains and even swell the pores due to its high polarizability and quadrupole moment (Sung and Suh 2014). Although recently reported PEI (40 wt\%) $\subset$ PAF-5 (Sung and Suh 2014) exhibited even higher selectivity (1200, $298 \mathrm{~K}$ ) than $\mathrm{FC}-\mathrm{POP}-\mathrm{CH}_{2} \mathrm{PEI}$, the latter still stands out in regards to the physicochemical stability arising from covalent bonding amine to the network. Overall, the selectivity value relies on pore structure and $\mathrm{CO}_{2}$ adsorption enthalpies of polymers, so the adjustment of task- 
Table 3 Summary of surface area, $\mathrm{CO}_{2}$ uptake, selectivity and adsorption enthalpy $(Q \mathrm{st})$ in selected POPs (with excellent reported results)

\begin{tabular}{|c|c|c|c|c|c|c|}
\hline POPs & $S_{\mathrm{BET}}\left(\mathrm{m}^{2} / \mathrm{g}\right)$ & $\mathrm{T}(\mathrm{K})$ & $\mathrm{CO}_{2}$ uptake $(\mathrm{mmol} / \mathrm{g})$ & IAST selectivity & $Q_{\mathrm{st}}(\mathrm{kJ} / \mathrm{mol})$ & Ref. \\
\hline \multirow[t]{2}{*}{ FC-POP-CH${ }_{2} \mathrm{NH}_{2}$} & \multirow[t]{2}{*}{939} & 298 & 2.5 & 31.6 & \multirow[t]{2}{*}{37.9} & \multirow[t]{2}{*}{ This work } \\
\hline & & 273 & 4.2 & 40.9 & & \\
\hline \multirow[t]{2}{*}{ FC-POP- $\mathrm{CH}_{2}$ DETA } & \multirow[t]{2}{*}{636} & 298 & 3.4 & 167.8 & \multirow[t]{2}{*}{54.0} & \multirow[t]{2}{*}{ This work } \\
\hline & & 273 & 4.5 & 194.3 & & \\
\hline \multirow[t]{2}{*}{ FC-POP- $\mathrm{CH}_{2} \mathrm{PEI}$} & \multirow[t]{2}{*}{129} & 298 & 2.6 & 736.1 & \multirow[t]{2}{*}{64.0} & \multirow[t]{2}{*}{ This work } \\
\hline & & 273 & 3.2 & 720.8 & & \\
\hline \multirow[t]{2}{*}{ TB-MOP } & \multirow[t]{2}{*}{913} & 298 & 2.6 & 25 & \multirow[t]{2}{*}{30.2} & \multirow[t]{2}{*}{ (Zhu et al. 2014) } \\
\hline & & 273 & 4.1 & 46 & & \\
\hline \multirow[t]{2}{*}{ FCTF-1-600 } & \multirow[t]{2}{*}{1535} & 298 & 3.41 & 19 & \multirow[t]{2}{*}{30} & \multirow[t]{2}{*}{ (Zhao et al. 2013) } \\
\hline & & 273 & 5.53 & & & \\
\hline \multirow[t]{2}{*}{ CMP-1-(OH $)_{2}$} & \multirow[t]{2}{*}{1043} & 298 & 1.07 & & \multirow[t]{2}{*}{27.6} & \multirow[t]{2}{*}{ (Dawson et al. 2011) } \\
\hline & & 273 & 1.80 & & & \\
\hline \multirow[t]{2}{*}{ BILP-4 } & \multirow[t]{2}{*}{1135} & 298 & 3.59 & $32^{\mathrm{a}}$ & \multirow[t]{2}{*}{28.7} & \multirow[t]{2}{*}{ (Rabbani and El-Kaderi 2012) } \\
\hline & & 273 & 5.34 & $79^{\mathrm{a}}$ & & \\
\hline \multirow[t]{2}{*}{ PECONF-3 } & \multirow[t]{2}{*}{851} & 298 & 2.47 & 22 & 26 & (Mohanty et al. 2011) \\
\hline & & 273 & 3.49 & 60 & & \\
\hline azo-COP-2 & 729 & 298 & 1.53 & 130.6 & 24.8 & (Patel et al. 2013) \\
\hline & & 273 & 2.56 & 109.6 & & \\
\hline CPOP & 2220 & 273 & 4.82 & $25^{\mathrm{b}}$ & 27 & (Chen et al. 2012) \\
\hline Py-1 & 437 & 273 & 2.7 & $117^{\mathrm{a}}$ & 36 & (Luo et al. 2012) \\
\hline ALP-1 & 1235 & 273 & 5.37 & 40 & 29.2 & (Arab et al. 2014) \\
\hline & & 298 & 3.25 & 28 & & \\
\hline HBC-POP-1 & 688 & 298 & 1.2 & & & (Thompson et al. 2014) \\
\hline & & 273 & 2.1 & & & \\
\hline PPN-6-SO ${ }_{3} \mathrm{H}$ & 1254 & 295 & 3.6 & 150 & 30.4 & (Lu et al. 2011) \\
\hline $\mathrm{PPN}-6-\mathrm{SO}_{3} \mathrm{Li}$ & 1186 & 295 & 3.7 & 414 & 35.7 & (Lu et al. 2011) \\
\hline PPN-6- $\mathrm{CH}_{2}$ DETA & 555 & 295 & 4.3 & 442 & 56 & (Lu et al. 2012) \\
\hline $\mathrm{PEI}(40 \mathrm{wt} \%) \subset \mathrm{PAF}-5$ & 40.3 & 298 & 2.5 & $1200^{\mathrm{c}}$ & 68.7 & (Sung and Suh 2014) \\
\hline МСТР-1 & 1452 & 298 & 2.7 & $15.4^{\mathrm{a}}$ & 40.0 & (Puthiaraj et al. 2015) \\
\hline & & 273 & 4.6 & & & \\
\hline
\end{tabular}

specific microenvironment would be an effective approach to improve $\mathrm{CO}_{2} / \mathrm{N}_{2}$ selectivity.

To test the regeneration of the FC-POPs, cycling experiments were conducted on an ASAP 2020 analyzer (Fig. 5c). For each cycle, the adsorbents were saturated with $\mathrm{CO}_{2}$ up to 1 bar at $298 \mathrm{~K}$ followed by a high vacuum $(0.2 \mathrm{~Pa})$ at $80{ }^{\circ} \mathrm{C}$ for $90 \mathrm{~min}$. The $\mathrm{CO}_{2}$ adsorption capacity in each cycle almost reached the same point, with no apparent loss of uptake amount in the cycling test.

\section{Conclusions}

A highly porous FC-POP, which was facilely synthesized via Freidel-Crafts reaction, was incorporated by various amines to afford FC-POP- $\mathrm{CH}_{2} \mathrm{NH}_{2}$, FC-POP-CH${ }_{2}$ DETA and $\mathrm{FC}-\mathrm{POP}-\mathrm{CH}_{2} \mathrm{PEI}$. Both microporosity and excellent amine-affinity towards $\mathrm{CO}_{2}$ ensured those amine-functionalized polymers extraordinary $\mathrm{CO}_{2}$ selective adsorption performance. The $\mathrm{CO}_{2}$ adsorption capacity reached as high as $4.5 \mathrm{mmol} / \mathrm{g}$ at $273 \mathrm{~K}$ and $3.4 \mathrm{mmol} / \mathrm{g}$ at $298 \mathrm{~K}$ (1 bar) for FC-POP-CH 2 DETA; and the $\mathrm{CO}_{2} / \mathrm{N}_{2}$ selectivity soared to 736.1 at $298 \mathrm{~K}$ (1 bar) for FC-POP- $\mathrm{CH}_{2} \mathrm{PEI}$. The reason is, that the incorporation of task-specific functional groups would work as a dual regulations for the microenviroment of POPs. The dual regulations, namely the modifications of pore structure as well as the basic amine density, improved microporosity and adsorption enthalpy of $\mathrm{CO}_{2}$ apparently and further enhanced the $\mathrm{CO}_{2}$ capture performance.

Acknowledgements Financial supports for this study are provided by the National Key Technology Support Program of China (2013CB733501), the National Natural Science Foundation of China (Nos. 91334203, 21676080), the project of FP7-PEOPLE-2013IRSES (PIRSES-GA-2013-612230). 


\section{Compliance with ethical standards}

Conflict of interest The authors declare no competing financial interests.

Open Access This article is distributed under the terms of the Creative Commons Attribution 4.0 International License (http://crea tivecommons.org/licenses/by/4.0/), which permits unrestricted use, distribution, and reproduction in any medium, provided you give appropriate credit to the original author(s) and the source, provide a link to the Creative Commons license, and indicate if changes were made.

\section{References}

Arab P, Rabbani MG, Sekizkardes AK, İslamoğlu T, El-Kaderi HM (2014) Copper(I)-catalyzed synthesis of nanoporous azo-linked polymers: impact of textural properties on gas storage and selective carbon dioxide capture. Chem Mater 26:1385-1392. doi: $10.1021 / \mathrm{cm} 403161 \mathrm{e}$

Ben T et al (2009) Targeted synthesis of a porous aromatic framework with high stability and exceptionally high surface area. Angew Chem Int Ed 48:9457-9460. doi:10.1002/anie.200904637

Brennecke JF, Gurkan BE (2010) Ionic liquids for $\mathrm{CO}_{2}$ capture and emission reduction. J Phys Chem Lett 1:3459-3464. doi:10. $1021 / \mathrm{jz} 1014828$

Cai W et al (2014) Thermal structural transitions and carbon dioxide adsorption properties of zeolitic imidazolate framework-7 (ZIF7). J Am Chem Soc 136:7961-7971. doi:10.1021/ja5016298

Chen Q et al (2012) Microporous polycarbazole with high specific surface area for gas storage and separation. J Am Chem Soc 134:6084-6087. doi:10.1021/ja300438w

D'Alessandro DM, Smit B, Long JR (2010) Carbon dioxide capture: prospects for new materials. Angew Chem Int Ed 49:6058-6082. doi:10.1002/anie.201000431

Dawson R, Adams DJ, Cooper AI (2011) Chemical tuning of $\mathrm{CO}_{2}$ sorption in robust nanoporous organic polymers. Chem Sci 2:1173-1177. doi:10.1039/C1SC00100K

Dawson R, Stevens LA, Drage TC, Snape CE, Smith MW, Adams DJ, Cooper AI (2012) Impact of water coadsorption for carbon dioxide capture in microporous polymer sorbents. J Am Chem Soc 134:10741-10744. doi:10.1021/ja301926h

Goeppert A, Czaun M, Surya Prakash GK, Olah GA (2012) Air as the renewable carbon source of the future: an overview of $\mathrm{CO}_{2}$ capture from the atmosphere. Energy Environ Sci 5:7833-7853. doi:10.1039/C2EE21586A

Han Y, Zhang L-M, Zhao Y-C, Wang T, Han B-H (2013) Microporous organic polymers with ketal linkages: synthesis characterization, and gas sorption properties. ACS Appl Mater Interfaces 5:4166-4172. doi:10.1021/am400251h

Ilhan F, Gray M, Blanchette K, Rotello VM (1999) Control of polymer solution structure via intra- and intermolecular aromatic stacking. Macromolecules 32:6159-6162. doi:10.1021/ ma990724z

Jiang J-X et al (2009) Microporous poly(tri(4-ethynylphenyl)amine) networks: synthesis, properties, and atomistic simulation. Macromolecules 42:2658-2666. doi:10.1021/ma802625d

Li B et al (2011) A new strategy to microporous polymers: knitting rigid aromatic building blocks by external cross-linker. Macromolecules 44:2410-2414. doi:10.1021/ma200630s

Li L et al (2014) A crystalline porous coordination polymer decorated with nitroxyl radicals catalyzes aerobic oxidation of alcohols. J Am Chem Soc 136:7543-7546. doi:10.1021/ja5019095
Liao Y, Weber J, Faul CFJ (2014) Conjugated microporous polytriphenylamine networks. Chem Commun 50:8002-8005. doi:10. 1039/C4CC03026E

Liu D-P, Chen Q, Zhao Y-C, Zhang L-M, Qi A-D, Han B-H (2013) Fluorinated porous organic polymers via direct $\mathrm{C}-\mathrm{H}$ arylation polycondensation. ACS Macro Lett 2:522-526. doi:10.1021/ mz4001699

Lu W, Yuan D, Sculley J, Zhao D, Krishna R, Zhou H-C (2011) Sulfonate-grafted porous polymer networks for preferential $\mathrm{CO}_{2}$ adsorption at low pressure. J Am Chem Soc 133:18126-18129. doi:10.1021/ja2087773

Lu W, Sculley JP, Yuan D, Krishna R, Wei Z, Zhou H-C (2012) Polyamine-tethered porous polymer networks for carbon dioxide capture from flue gas. Angew Chem Int Ed 51:7480-7484. doi:10.1002/anie.201202176

Lu W, Verdegaal WM, Yu J, Balbuena PB, Jeong H-K, Zhou H-C (2013) Building multiple adsorption sites in porous polymer networks for carbon capture applications Energy. Environ Sci 6:3559-3564. doi:10.1039/C3EE42226G

Luo Y, Li B, Wang W, Wu K, Tan B (2012) Hypercrosslinked aromatic heterocyclic microporous polymers: a new class of highly selective $\mathrm{CO}_{2}$ capturing materials. Adv Mater 24:5703-5707. doi:10.1002/adma.201202447

Mohanty P, Kull LD, Landskron K (2011) Porous covalent electronrich organonitridic frameworks as highly selective sorbents for methane and carbon dioxide. Nat Commun 2:401

Myers AL, Prausnitz JM (1965) Thermodynamics of mixed-gas adsorption. AlChE J 11:121-127. doi:10.1002/aic.690110125

Patel HA, Hyun Je S, Park J, Chen DP, Jung Y, Yavuz CT, Coskun A (2013) Unprecedented high-temperature $\mathrm{CO}_{2}$ selectivity in $\mathrm{N}_{2^{-}}$ phobic nanoporous covalent organic polymers. Nat Commun 4:1357

Puthiaraj P, Cho S-M, Lee Y-R, Ahn W-S (2015) Microporous covalent triazine polymers: efficient Friedel-Crafts synthesis and adsorption/storage of $\mathrm{CO}_{2}$ and $\mathrm{CH}_{4}$. J Mater Chem A 3:6792-6797. doi:10.1039/C5TA00665A

Rabbani MG, El-Kaderi HM (2012) Synthesis and characterization of porous benzimidazole-linked polymers and their performance in small gas storage and selective uptake. Chem Mater 24:1511-1517. doi:10.1021/cm300407h

Romanov V, Graeser L, Jikich S, Soong Y, Irdi G (2015) Coal-gas interaction: implications of changes in texture and porosity. Int J Coal Sci Technol. doi:10.1007/s40789-015-0098-6

Service RF (2004) Choosing a $\mathrm{CO}_{2}$ separation technology. Science 305:963. doi:10.1126/science.305.5686.963

Sevilla M, Fuertes AB (2011) Sustainable porous carbons with a superior performance for $\mathrm{CO}_{2}$ capture Energy. Environ Sci 4:1765-1771. doi:10.1039/C0EE00784F

Suhendi A, Nandiyanto ABD, Munir MM, Ogi T, Gradon L, Okuyama K (2013) Self-assembly of colloidal nanoparticles inside charged droplets during spray-drying in the fabrication of nanostructured particles. Langmuir 29:13152-13161. doi:10. 1021/la403127e

Sumida K et al (2011) Carbon dioxide capture in metal-organic frameworks. Chem Rev 112:724-781. doi:10.1021/cr2003272

Sung S, Suh MP (2014) Highly efficient carbon dioxide capture with a porous organic polymer impregnated with polyethylenimine. J Mater Chem A 2:13245-13249. doi:10.1039/C4TA02861A

Thomas A (2010) Functional materials: from hard to soft porous frameworks. Angew Chem Int Ed 49:8328-8344. doi:10.1002/ anie. 201000167

Thompson CM, Li F, Smaldone RA (2014) Synthesis and sorption properties of hexa-(peri)-hexabenzocoronene-based porous organic polymers. Chem Commun 50:6171-6173. doi:10.1039/ $\mathrm{C} 4 \mathrm{CC} 02213 \mathrm{~K}$ 
Wakihara T, Sato K, Inagaki S, Tatami J, Komeya K, Meguro T, Kubota Y (2010) Fabrication of fine zeolite with improved catalytic properties by bead milling and alkali treatment. ACS Appl Mater Interfaces 2:2715-2718. doi:10.1021/am100642w

Wang J, Xu S (2014) $\mathrm{CO}_{2}$ capture RD\&D proceedings in China Huaneng Group. Int J Coal Sci Technol 1:129-134. doi:10.1007/ s40789-014-0013-6

Woodward RT et al (2014) Swellable, water- and acid-tolerant polymer sponges for chemoselective carbon dioxide capture. J Am Chem Soc 136:9028-9035. doi:10.1021/ja5031968

Xu S, Song K, Li T, Tan B (2015) Palladium catalyst coordinated in knitting N-heterocyclic carbene porous polymers for efficient Suzuki-Miyaura coupling reactions. J Mater Chem A 3:1272-1278. doi:10.1039/C4TA05265J

Yuan D, Lu W, Zhao D, Zhou H-C (2011) Highly stable porous polymer networks with exceptionally high gas-uptake capacities. Adv Mater 23:3723-3725. doi:10.1002/adma.201101759

Zhang C, Liu Y, Li B, Tan B, Chen C-F, Xu H-B, Yang X-L (2012) Triptycene-based microporous polymers: synthesis and their gas storage properties. ACS Macro Lett 1:190-193. doi:10.1021/ mz200076c

Zhao Y-C, Wang T, Zhang L-M, Cui Y, Han B-H (2012) Facile approach to preparing microporous organic polymers through benzoin condensation. ACS Appl Mater Interfaces 4:6975-6981. doi:10.1021/am302163p

Zhao Y, Yao KX, Teng B, Zhang T, Han Y (2013) A perfluorinated covalent triazine-based framework for highly selective and water-tolerant $\mathrm{CO}_{2}$ capture. Energy Environ Sci 6:3684-3692. doi:10.1039/C3EE42548G

Zhu Y, Zhang W (2014) Reversible tuning of pore size and $\mathrm{CO}_{2}$ adsorption in azobenzene functionalized porous organic polymers. Chem Sci 5:4957-4961. doi:10.1039/C4SC02305F

Zhu X et al (2013) Efficient $\mathrm{CO}_{2}$ capture by a 3D porous polymer derived from Tröger's base. ACS Macro Lett 2:660-663. doi:10. $1021 / \mathrm{mz} 4003485$

Zhu X et al (2014) Efficient $\mathrm{CO}_{2}$ capture by a task-specific porous organic polymer bifunctionalized with carbazole and triazine groups. Chem Commun 50:7933-7936. doi:10.1039/C4CC01588F 